\title{
Port's technologies for autonomous ships in restricted waters
}

\author{
Helio Takahiro Sinohara
}

Department of Mechanics Engineering, Universidade de São Paulo, Sao Paulo, Brazil and Paranagua Pilots, Paranagua, Brazil, and

Eduardo Aoun Tannuri

Mechatronics Engineering, Universidade de São Paulo, Sao Paulo, Brazil

\begin{abstract}
Purpose - This work analyses autonomous ships' specific needs of external and environmental information in restricted pilotage waters. Harbour pilots use conventional well-tested techniques when piloting the manned vessel. In this work, the authors propose technological solutions to be installed or adapted in ports to feed the autonomous ships' systems with the information considered relevant by pilots.

Design/methodology/approach - To investigate what pilots consider relevant, the authors submitted a questionnaire to the pilotage of Paranagua Port. Then the authors presented a case study including the critical areas for the navigation of ships.

Findings - These technological solutions aim to allow vessels reaching critical areas in a position, a time, a speed and a course that compensates the external forces and/or avoid high-risk situations. The authors have proposed technological solutions considering those already available in the ports, particularly in Paranaguá and Antonina in Brazil.

Originality/value - There is little published data on navigation of ships in pilotage waters. So far, there has been little discussion on autonomous ships in restricted waters.
\end{abstract}

Keywords Autonomous ships, Port, Pilot, Pilotage, Restricted waters, Paranaguá, Brazil

Paper type Research paper

\section{Introduction}

Navigation in restricted pilotage waters is quite different from the one in deep-sea conditions. There are higher risks involved when compared to sailing in the open sea. Knowledge of the particular waterway and expertise in ship handling is imperative. Shallow and congested waters, rocks, the proximity of ports, buoys, no-go areas, other hazards and the more significant influence of environmental forces when vessels proceed at lower speeds will require more precise and skilful manoeuvres and navigation. In such areas, professionals known as marine pilots board ships and, based on their experience, use techniques learned and tested over the years to safely conduct vessels to the destination. Besides their deep knowledge of the seabed and the skills in handling any type and size of the ship, they must keep the situational awareness considering all factors that may influence the passage, such as type of bottom, wind, current, tide, waves, visibility and traffic.

Similarly, we expect the autonomous ships to be highly manoeuvrable in restricted waters and consider seabed depths when planning the passage. However, to conduct safe navigation in those waterways, that is not enough. It will likely be necessary for the autonomous ship to consider the same external factors that pilots do. For instance, the internal vessels' equipment and sensors can measure the prevailing wind and current at the ship's location and detect the automatic identification system (AIS) targets in their vicinities. Nevertheless, the pilots do not

(C) Pacific Star Group Education Foundation. Licensed re-use rights only.

The authors thank the Paranaguá pilots for the valuable discussions and the collaboration.
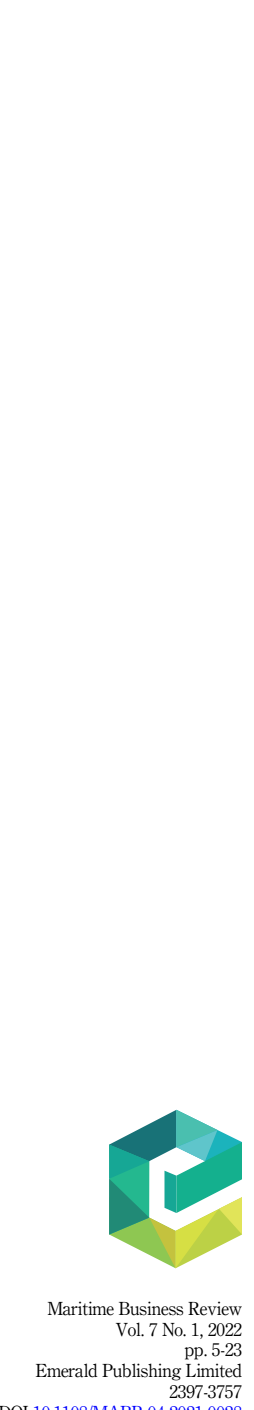
MABR

7,1

\section{6}

consider only the forces acting upon the ship at the present location. They also estimate how strong those forces and other influences will be in the future when the ship reaches a critical area. In addition, speed is controlled to avoid meeting vessels in unsafe areas, prevent reaching narrow passages in dangerous conditions and wait for tugs availability. In this paper, we considered critical areas as those where the risks for ships' navigation or meeting manoeuvres with other vessels are higher than in most other areas. Examples are areas with strong influences of current, waves or wind; narrow areas where a ship cannot meet another ship and vicinities of rocks and other dangers to navigation.

In order to provide the autonomous ship with the required information to enter restricted pilotage waters, ports should be adapted and upgraded. Nevertheless, many sensors and types of equipment already installed in some ports could be used to provide some of the required data. The solutions proposed in this work should be useful in ports called by all four degrees of Maritime Autonomous Surface Ships (MASS) as defined by the International Maritime Organization (IMO). From degree on, with seafarers on board to operate and control shipboard systems and functions, to degree four, a fully autonomous ship.

\subsection{Role of the pilotage}

According to the International Maritime Pilots' Association (2020), "Pilots are highly trained experts in ship navigation in specific waters and possess extensive knowledge of local conditions. Their role is to guide vessels safely and expeditiously through their area ensuring safety of the environment, people and trade". Usually, pilots come onboard ships climbing a ladder rigged over the vessel's side (see Plate 1). She may be at anchor, alongside or even underway. As local experts, pilots assist captains when sailing and manoeuvring in restricted waters that require
Plate 1.

Pilot climbing a ladder

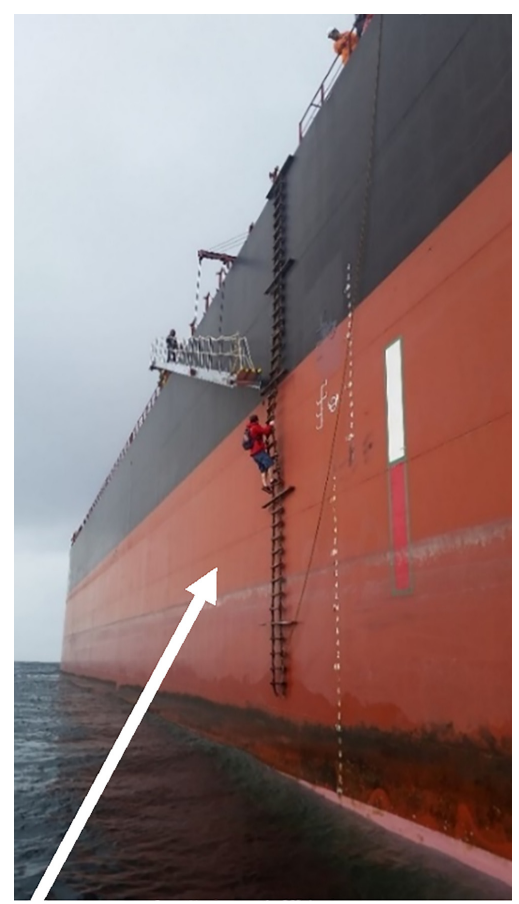


local knowledge to conduct a safe passage. Such knowledge includes the depths, environmental forces, language, traffic and any other local specific characteristic or hindrance that may interfere in the manoeuvre. With high-level ship handling skills, pilots also contribute to the port efficiency while managing the traffic and free flow in the port area, providing a critical public safety service.

During navigation and manoeuvre, pilots give instructions to tugs' crew to mooring men and ship's crew. In addition, they communicate with pilots on board other ships, with the Pilot

Station and with the Vessel Traffic Control centre to exchange information and maintain situational awareness during all the passage.

Anticipation is at the core of the pilot's job. Wahlström (2019) observed this in simulator trials with pilots. From the comparison between stopping a car and stopping a ship, it is possible to understand why. A car moving at $15 \mathrm{Km} / \mathrm{h}$ can easily stop in a few seconds after advancing only 10 metres. On the other hand, a typical medium-size ship at the same speed would take up to $10 \mathrm{~min}$ and might require about 1.800 metres to stop. This means that pilots need to know how to advance the conditions they will face in critical areas to plan how to compensate for external forces and influences or even avoid dangerous situations by controlling the ship's speed.

However, there are situations when unexpected external forces affect the ship, so that it is not possible to avoid an accident. Nevertheless, in similar conditions, if the pilot is aware of those forces early enough, he can compensate for its effects before the vessel is affected and make it a routine manoeuvre instead of a dangerous passage.

The arrival of autonomous ships will affect the whole community that works directly with ships to a greater or lesser degree. It will not be different with the pilotage. Considering that the pilotage's role is currently essential for the safety of many ports, it is necessary to study the impacts that autonomous ships will bring to the navigation in these areas and how will the transition between the current and the future model take place. Many pilots around the world are closely observing the evolution and developments on this subject. Although the Brazilian Pilotage is not encouraging the introduction of autonomous ships in restricted waters, they keep up with the latest MASS discussions and initiatives and are open to participating when invited.

In the following section, a literature review on pilotage and ports for autonomous ships is presented. Next, Section 3 details the external factors that most Paranaguá pilots consider relevant for safe navigation/manoeuvre. Section 4 describes the methodology used to obtain information and propose a solution. Section 5 describes the Paranaguá Port, discussing the upgrades that ports and pilotage waters control centres should implement to supply autonomous ships with the data mentioned in Section 4. Next, we analyse a case study based on a critical passage in Galheta Channel (Paranaguá Port). Finally, Section 6 brings the conclusions of this paper.

\section{Literature review}

Autonomous shipping is a complex matter with various aspects and possible approaches. From the ship's perspective, several works on situational awareness (Khellal, 2018; Lee, 2018), navigational control (Perera, 2015) and collision avoidance (Johansen, 2016; Perera, 2015; Statheros, 2008) are available in the literature or being conducted. However, when approaching restricted waterways, conditions may require a new perspective. Even manned vessels frequently require a professional's assistance who possesses deep knowledge on the particulars of the port approach, the pilot. The importance of pilot's assistance is well known, as explained in Almeida's (2019) work.

Many works on autonomous ship navigation in restricted waters are based on reactive techniques, like in Lyu (2018). Nevertheless, some situations cannot avoid an accident when 
MABR

7,1

8

reacting to external forces after the ship is affected. In Boogaard (2016), human assistance was assumed to be necessary for navigating autonomous ships in ports in critical situations.

Port infrastructure to receive autonomous ships is being developed (Fiedler, 2019). Nevertheless, we identified a gap in the research on port infrastructure for autonomous ships. Therefore, it is necessary to deal with specific requirements imposed on ships by the waterways' restrictions in pilotage waters. Many studies, like Burmeister (2014), are focused on autonomous ships' aspects in the open sea. From the ship handler perspective, our research proposal is based on specific requirements to manoeuvre vessels in pilotage waters. As such, the paper contributes to the body of the literature.

\section{External influences in navigation and manoeuvring}

During the navigation of manned vessels, marine and river pilots collect information from several sources before giving helm, engine and tug orders. They manage risks to maximise the port, the ship and the fairway safety and efficiency. To obtain the required information, pilots may observe the surroundings and other vessels, check tide tables/weather forecasts, communicate by very high frequency (VHF) radio and use their knowledge about the region.

In the following subsections, we describe some of the main external factors, forces and influences that pilots observe during the navigation in restricted waters, including most of those mentioned by Paranaguá pilots in the survey that will be detailed in Section 4 . This description includes several old-fashioned techniques frequently used by pilots to obtain information about these external forces or influences. The pilots described these observation methods and techniques during the preliminary survey or directly observed by one of the authors during his pilotage job in Paranaguá. In some of the subsections, we also included information about current sensors to assist the pilots.

\subsection{Current}

The current is an essential element to be considered in pilotage areas. Not only the ship's longitudinal speed is affected but her lateral speed and manoeuvrability as well. Therefore, the current's direction and intensity must be considered when planning the navigation, anchoring and berthing/unberthing manoeuvres. In addition, pilots use the current to assist in the manoeuvres instead of fighting against it.

How do the pilots estimate the current? There are several traditional ways. They can observe the objects on the water surface. Anything adrift, like floating leaves, can be used to estimate the surface's current speed. The wake and inclination of buoys (Plate 2) indicate the influence of the current. The pilots can calculate the current's direction and intensity by the time to, or after, the slack water and the moon phase. They can also look at anchored ships and check their anchor chain (Plates 3a and 3b) direction and tightness.

Plate 2.

Buoy in a strong current

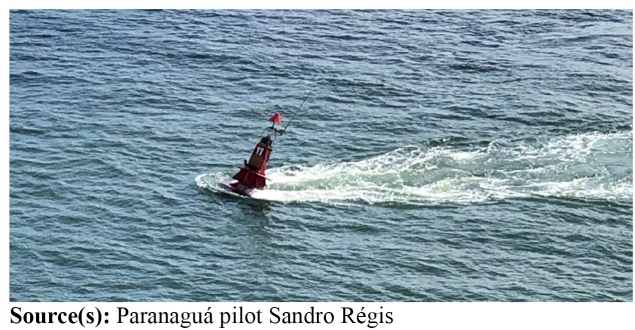

Source(s): Paranaguá pilot Sandro Régis 


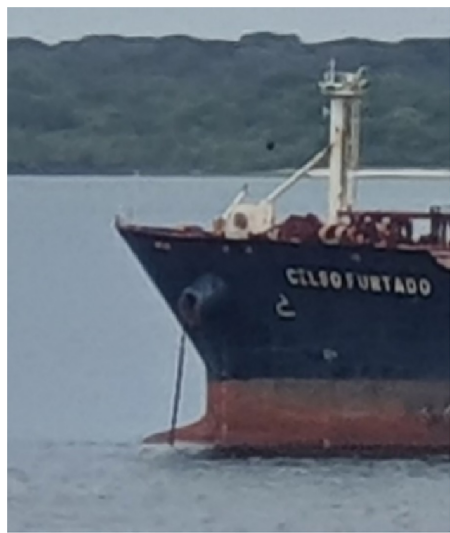

(a)

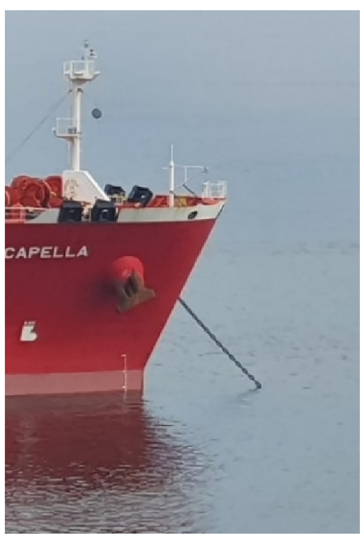

(b)
Autonomous

ships

9

Plate 3.

Ships at anchor with slack (a) and tight chain (b)

Electronic current sensors are available in two locations (Terminal de Contêineres de Paranaguá and Cattalini Terminal). Although the pilots may use the information from these sensors, they do not abandon the traditional methods as a double-check procedure, constantly evaluating the influence of the resultant force in the ship.

\subsection{Tide}

The tide height and direction of the water flow are factors to be considered in the passage plan. They affect the maximum safe draft and the intensity and direction of the current. The pilots can check if the tide is ebb or flood observing the anchored vessels. The heading of these vessels and the anchor chain's tightness (Plates 3a and 3b) indicate if the tide is flood, ebb or transition, although strong winds can also change the vessels headings.

Another pilots' method to assess the tide height is to observe if rocks and fenders are under or out of the water. By doing this, they can compare the water level to the position of known fixed objects. For example, in Plate 4, we can observe that the fenders are partially submerged, and a dark mark is visible in the areas frequently submerged in high water.

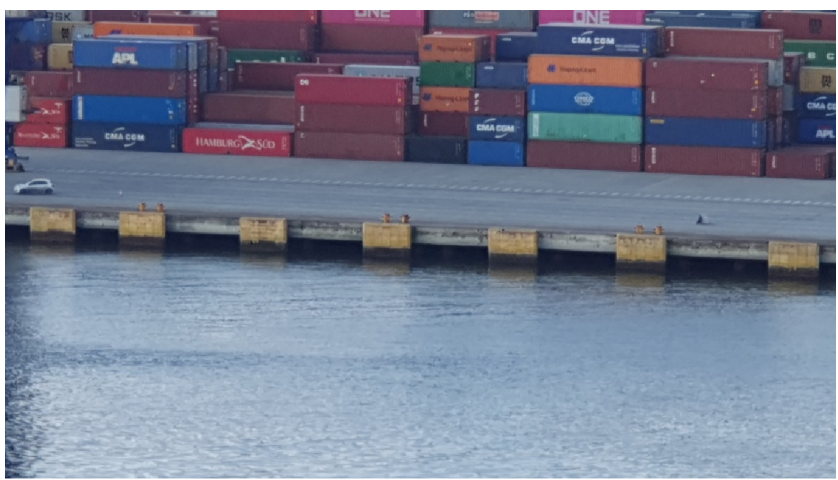

Plate 4.

Fenders partially submerged 


\section{MABR \\ 7,1}

10

\subsection{Wind}

Strong winds may affect navigation and manoeuvrability, especially for large windage vessels, like container ships, ro-ro and cruisers. Particularly at low speeds, as when anchoring, berthing, unberthing or just waiting for favourable conditions (like availability of berth or tugs), the wind may change the ship's heading. Pilots observe flags (Plate 5), vapour and smoke (Plate 6), wind indicator on board and the wind forecast. Anemometres and anemoscopes located in strategic port positions, like those found in Paranaguá, are helpful to anticipate the near future wind conditions. At the same time, X-band radar in high range scales can reveal approaching storms that may cause strong gusts. For example, the Ocean Data Acquisition System (ODAS) buoy (Plate 7) installed in the vicinities of the Galheta Channel entrance in Paranaguá sends gusts and prevailing wind speed to the pilot station.

\subsection{Visibility}

Low visibility increases the risks to navigation. The surroundings' situation can be assessed by eye, but some critical passages may be out of reach. Therefore, the decision to abort and proceed to the anchorage depends on the information gathered while navigating along the

Plate 5.

Flags in strong wind
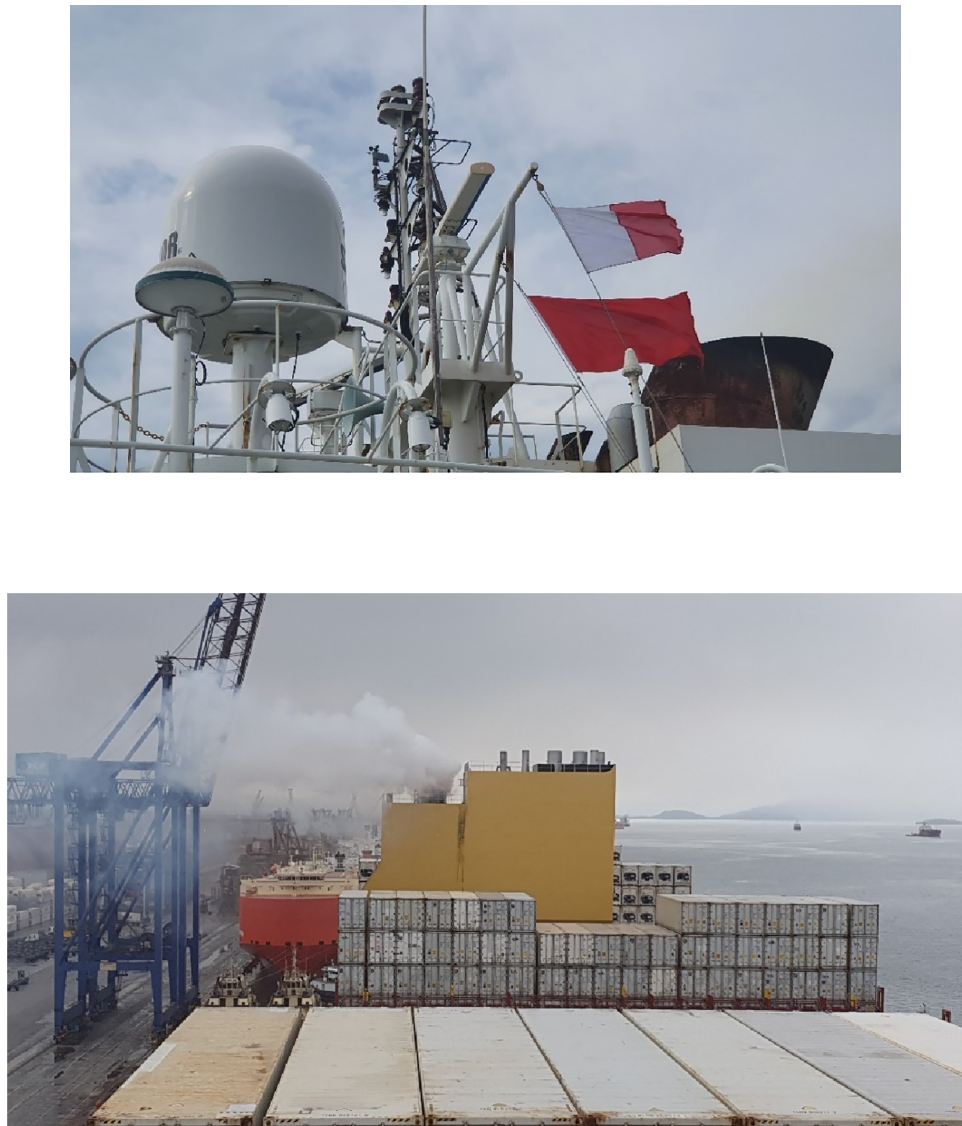

\section{Plate 6.}

Wind towards the berth and its influence in the ship's vapour 


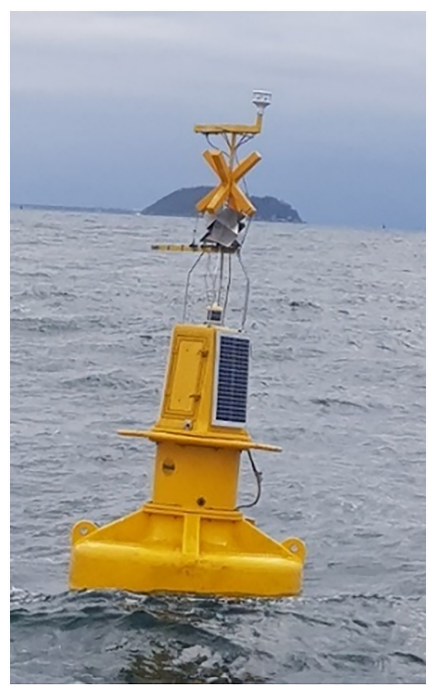

Autonomous

ships

11

Plate 7.

ODAS buoy

channel. As the vessel proceeds, pilots are informed about visibility by tugs, high-resolution cameras in strategic spots and/or visibility metres, like those in ODAS buoys used to check the visibility from distant locations.

\subsection{Waves}

Big waves may be a hindrance during pilots' boarding and disembarking procedures. However, even in unmanned ships, it may affect the manoeuvrability and the dynamic draft to restrict the navigation of loaded vessels in shallow areas. As the open sea is about 15 nautical miles away from the Paranaguá Port, the pilots evaluate the sea state when proceeding to an inbound vessel on board the pilot boat or onboard an outbound vessel. Nowadays, they also use the ODAS buoy. In addition, VHF contact with ships anchored in the open sea contributes to the sea state evaluation.

\subsection{Expected traffic and ships at berth or anchorage}

Ships in the turning basin, in critical passages, narrow channels, loaded or carrying dangerous cargo may interfere with other vessels' passage. Even vessels alongside may be an obstacle to using some channels, especially if the environmental conditions require higher speeds to avoid excessive set. Proceed at high speeds could cause damage to the mooring lines and gangway of the ship alongside or to the cranes. Crowded anchorages may restrict contingency options and meeting areas (where ships may safely encounter other ships and manoeuvre to avoid collision). Even small boats in the channel or crossing it could contribute to accidents. AIS, electronic chart display and information system (ECDIS), visual, radar and VHF are used to improve situational awareness to allow the pilots to calculate the speed to reach critical areas when the prevailing conditions are good enough. However, some small boats and other targets may be out of range for the ship's instruments. If the pilot is, in advance, aware of the presence of these targets, he can be prepared to take actions to prevent collisions or other accidents. 


\section{MABR \\ 7,1}

\subsection{Weather forecast}

The weather forecast is frequently checked to prepare the mooring lines and avoid manoeuvring during unsafe wind/wave conditions. This may delay the beginning of the passage or slow down the ships to wait for the conditions to improve.

\subsection{Tug availability}

Lack of availability of tugs with enough bollard pull while assisting other vessels may also delay the manoeuvres. The pilot should be informed to slow down the ship or proceed to an anchorage area as early as possible. Pilots use the VHF to contact the tugs.

\section{Methodology and survey outcome}

\subsection{The preliminary survey}

To investigate which are the most relevant external factors that should be considered during the navigation in pilotage waters, we had the assistance of the Paranaguá and Antonina marine pilots. A preliminary survey was conducted questioning some pilots about the information they require to conduct navigation or manoeuvre. In this step, pilots were also invited to indicate which were the most critical passages for the navigation of ships in the Paranaguá Port and its access. The purpose of this preliminary survey was to obtain the necessary information to allow us to elaborate a formal questionnaire that would be sent to all Paranaguá pilots.

Seven pilots were interviewed in this preliminary survey, and we focused on the information that should be obtained externally and not available in the ships' instruments. Therefore, using only open-ended questions, we asked them which are the critical areas for ships' navigation in Paranaguá ports and Galheta Channel (the access channel to Paranaguá ports)? We also asked them which are the external factors they observe and consider during the navigation?

From the preliminary survey results, we were apprised of two of the most critical passages for Paranaguá pilots: the entrance of Galheta Channel (area A, Figure 2) and the passage in area $\mathrm{F}$ (Figure 3). All the seven pilots informed that the relevant external factors are current at critical areas; tide; wind; visibility; occupied berths and prospects of availability; occupied anchorages and prospects of availability; expected traffic; weather forecast and tug availability. We prepared a second survey (a questionnaire) and sent it to the pilots based on this information. The paragraphs that follow describe the survey being conducted.

\subsection{The questionnaire}

With the outcome of the preliminary survey, a new survey questionnaire was designed. This second survey focused on identifying the main influences on the pilotage navigation/ manoeuvre to allow the proposal equipment and systems to supply such information; it consisted of two questions. These questions' purpose was to investigate the information that pilots consider relevant during the ships manoeuvre or navigation in the Paranaguá Port or its access channel, with regard only to the information NOT AVAILABLE ONBOARD (in the ships' instruments and sensors).

Question 1 investigated which factors, influences or information should pilots consider when planning or conducting pilotage navigation or manoeuvre? These factors, influences or information include (1) current at critical areas; (2) tide; (3) wind; (4) visibility; (5) occupied berths and prospects of availability; (6) occupied anchorages and prospects of availability; (7) expected traffic; (8) weather forecast and (9) tug availability. In this context, this question investigated how pilots estimate the above factors without using electronic equipment or sensors and how pilots would obtain the information if electronic equipment and sensors 
were available. In the current survey, sensors include current, wind and visibility sensors, weather stations, maregraphs and similar ones.

Question 2 investigated if there were other factors, influences or information not mentioned in Question 1 that should be taken into account. In case of a positive answer, pilots were invited to indicate them and reveal how they could estimate them without the assistance of electronic equipment or sensors. Besides, pilots were asked how they would obtain the information if electronic equipment and sensors were available.
Autonomous ships

\subsection{Survey outcome}

A total of 32 pilots are working in the Paranaguá pilotage area. 20 of these pilots answered the questionnaire, representing a total of $62.5 \%$ of the population. Additional information about the population is presented in the following paragraphs. Pilots' ages range from 33 to 69; their average age is 45 years. They have been working at Paranaguá pilotage for between 2 and 32 years; therefore, their average experience level is nine years. The outcome of the survey is shown in Figure 1.

For each of the factors shown in Figure 1, the pilots also described how they obtain the required information without port sensors or electronics. Although, in some cases, there are sensors available in Paranaguá and Antonina ports, pilots frequently double-check the information obtained using old-fashioned, reliable techniques. Nevertheless, all 20 pilots participating in this survey informed that they are already using some information from the available sensors and/or they would use the data from new sensors and support systems if available. The traditional navigation and situational awareness techniques described in this paper have been used by pilots and seafarers worldwide and were listed after a survey with the Paranaguá and Antonina pilots. However, each port (or restricted waterway) has its peculiarities. Therefore, this work does not intend to cover all possible external factors that should be considered in all pilotage waters.

When answering Question 2, some pilots suggested that other factors be considered during a safe passage or manoeuvre. These include

(1) Mooring men availability: one pilot considers it essential to know if the mooring men will be on standby and ready when the ship approaches the berth.

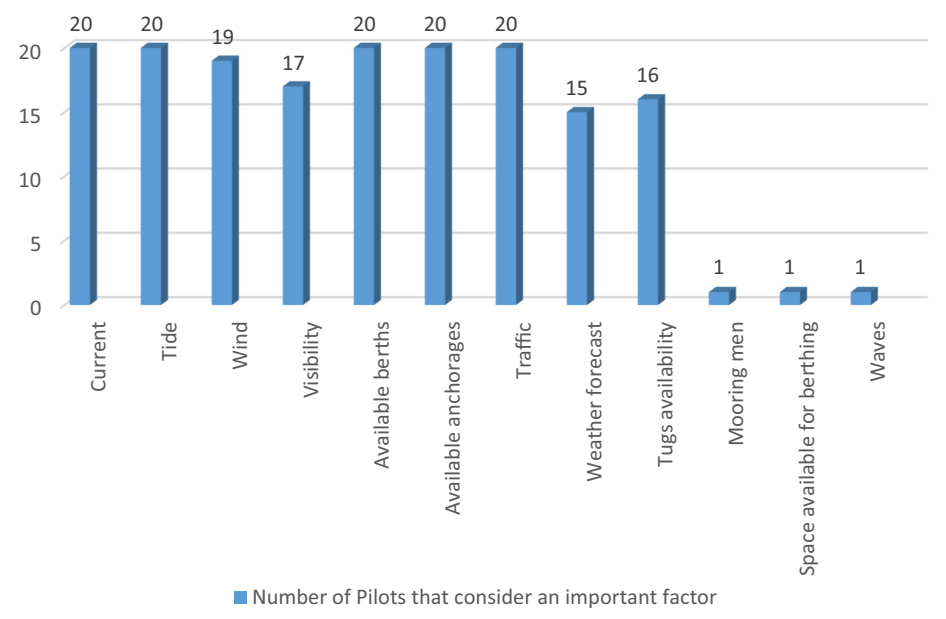

Figure 1.

Survey results Important factors for navigation and manoeuvre 
MABR
7,1

14

Figure 2.

Pilot boarding area and Galheta Channel

Figure 3.

Paranaguá and Antonina ports

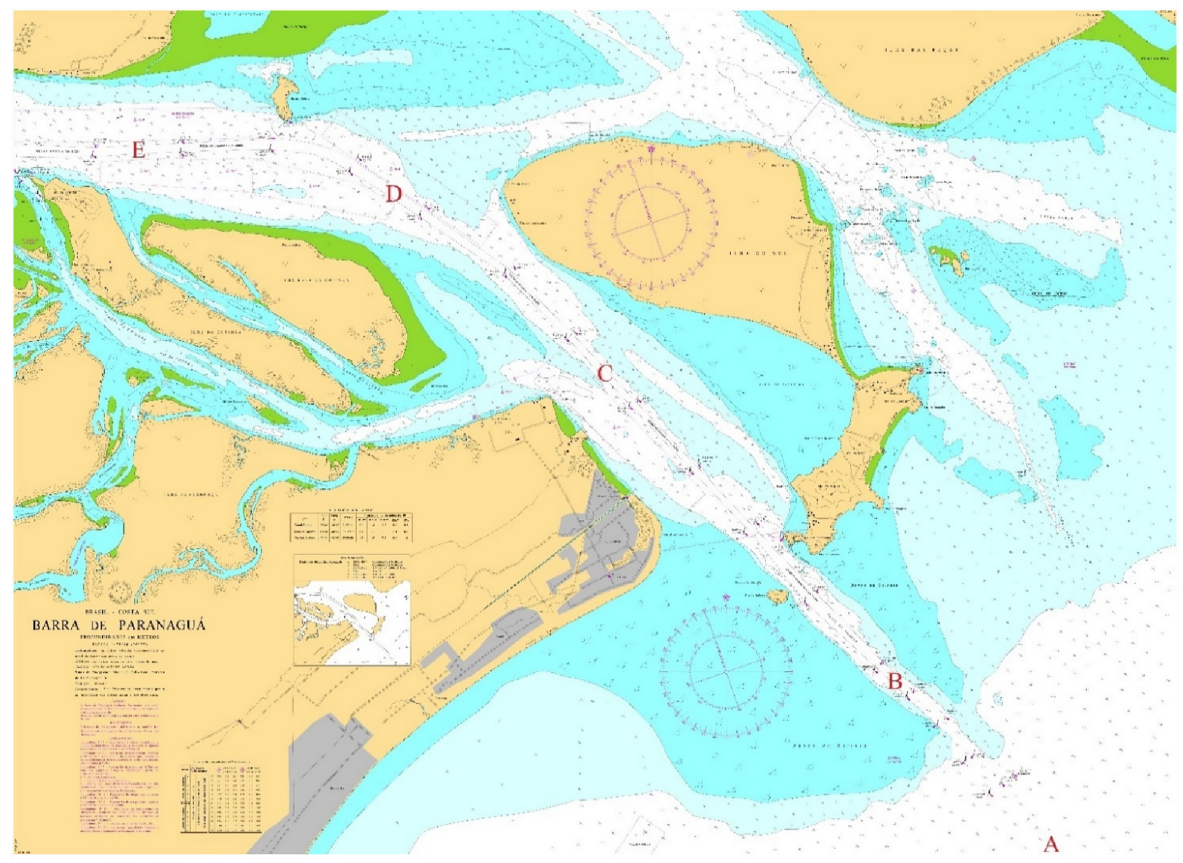

Source(s): Nautical Chart 1821 - Brazilian Navy

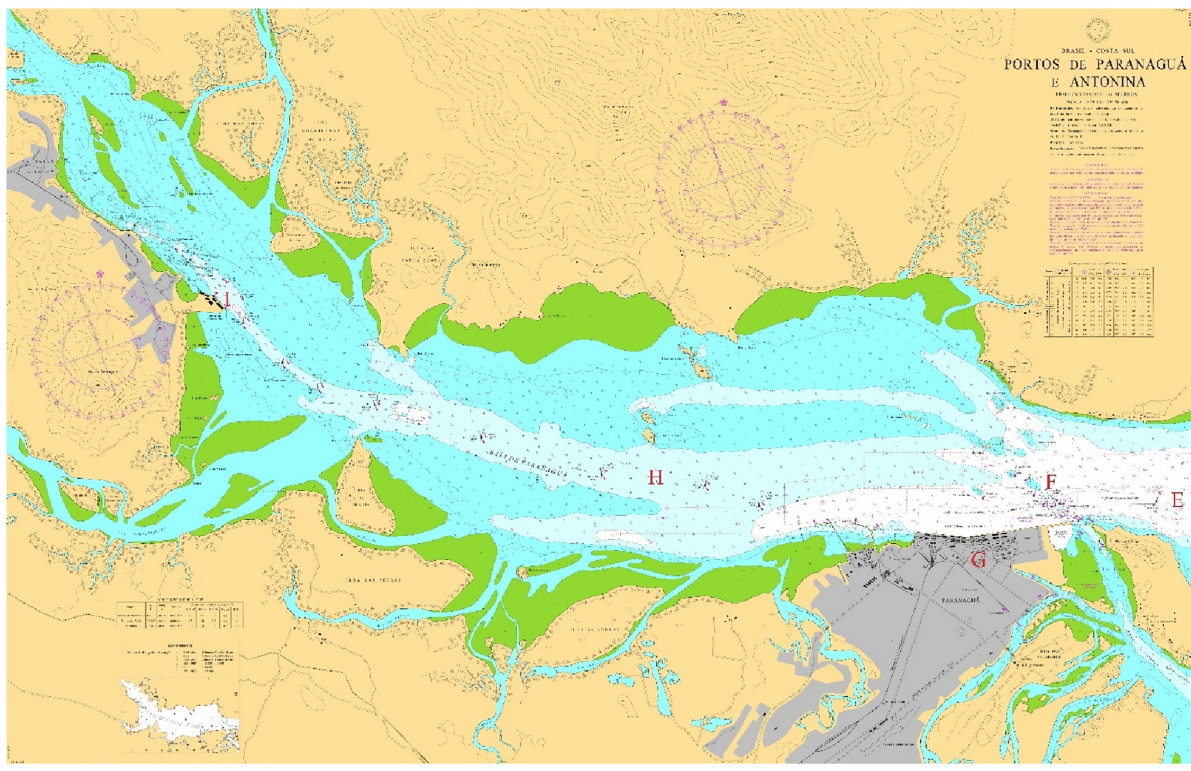

Source(s): Nautical Chart 1822 - Brazilian Navy 
(2) Space available in the berth: one pilot informed that the final distance to the surrounding ships and the total space available in the berth also would interfere in the approach and navigation.

(3) Waves: one pilot considers it important to know the height of the waves at the entrance of the Galheta Channel.

In the following paragraphs, we present the questionnaire results regarding the oldfashioned, reliable techniques used by the pilots.

(1) Current: The pilots reported that they estimate the current by (a) Observing the wake of buoys (19 pilots); (b) Observing the heading of anchored vessels and the tightness of the anchor chain (12 pilots); (c) Observing the wake of the pier columns: 2 pilots and (d) Observing the wake of ships (1 pilot).

(2) Tide: The pilots reported that they estimate the tide by (a) Observing known objects, as fenders, rocks and the beach (15 pilots); (b) Observing heading of anchored vessels and the tightness of the anchor chain (2 pilots); (c) Checking tide table (2 pilots) and (d) Checking a tide ruler at the pilot station (1 pilot).

(3) Wind: The pilots reported that they estimate the wind by (a) Observing the water surface and waves (14 pilots); (b) Observing smoke from the chimneys (6 pilots); (c) Feeling the wind in the ship's wing (6 pilots); (d) Looking at the ships' flags (5 pilots); (e) Observing heading of anchored vessels and the tightness of the anchor chain (4 pilots); (f) Observing windsocks (2 pilots); (g) Observing trees (1 pilot) and (h) Questioning other vessels by radio (1 pilot).

(4) Visibility: The pilots reported that they estimate the visibility by (a) Observing objects and checking the distance with radar or other means (18 pilots) and (b) Contacting other stations by radio to ask about visibility (2 pilots).

(5) Berth availability: The pilots reported that they check the berth availability by (a) Contacting the Pilot Station by radio or checking the report of scheduled manoeuvres (16 pilots); (b) Contacting tugs to check the status of manoeuvres (2 pilots); (c) Contacting ships by radio to check the status and intention (2 pilots); (d) Contacting the terminal (1 pilot) and (e) Looking at the berths with binoculars (1 pilot).

(6) Anchorage availability: The pilots reported that they check the anchorage availability by (a) Contacting the Pilot Station by radio or checking the report of scheduled manoeuvres (15 pilots); (b) Looking at the anchorages with binoculars (6 pilots) and (c) Contacting the terminal (1 pilot).

(7) Expected traffic: The pilots reported that they get the information about expected traffic by (a) Contacting the Pilot Station by radio or checking the report of scheduled manoeuvres (19 pilots) and (b) Looking with or without binoculars (4 pilots).

(8) Weather forecast: The pilots reported that they keep informed about the weather forecast by (a) Checking websites, mobile phone apps or weather reports (12 pilots); (b) Observing the clouds (8 pilots); (c) Checking wind, temperature and/or barometric pressure (5 pilots) and (d) Contacting ships and land stations to ask about the weather (1 pilot).

(9) Tug availability: The pilots reported that they check the tug availability by (a) Contacting tugs by radio (16 pilots) and (b) Contacting the Pilot Station by radio or checking the report of scheduled manoeuvres (11 pilots). 
MABR

7,1

\section{6}

(10) Mooring men availability: The pilots reported that they check the mooring men readiness by (a) Contacting mooring men by radio ( 1 pilot) and (b) Contacting the Pilot Station by radio and asking to phone call the mooring men (1 pilot).

(11) Space available for berthing: The pilots reported that they check the space available for berthing by (a) Contacting the Pilot Station by radio and asking to phone call the terminal (1 pilot).

(12) Waves: The pilots reported that they get informed about the condition of the waves by (a) Contacting the pilot boat at open sea (Pilot Boarding area) (1 pilot) and (b) Contacting vessels at open sea anchorage by radio (1 pilot).

From the analysis of the information given by the pilots in the questionnaire, we proposed, for each relevant factor to navigation or manoeuvre, technological solutions that can provide the required information to the pilots or an autonomous ship in a particular restricted channel. These solutions contribute to preparing ports to receive autonomous ships, thus overcoming the local conditions' restrictions during the approaches. Nevertheless, the proposed solution will also help pilots working on manned vessels, improving the quality, precision and reliability of required information during navigation or manoeuvre. To illustrate our proposal, we elaborated a case study demonstrating how these solutions can assist autonomous ships in critical passages of the Paranaguá Port.

\section{Case study: the Paranaguá port, Brazil}

Each port in the world that will receive autonomous ships will require specific solutions to provide the necessary information to these vessels. This section discusses the Paranaguá Port case and how it could be adapted to be prepared for this future demand. The survey's outcome revealed critical areas and the main factors to be considered during the navigation in Galheta Channel. Based on this outcome, we prepared this case study, including the solutions that could be implemented to provide a MASS with the data needed to conduct a safe passage in the two areas considered critical by the pilots that participated of the survey.

First, in Subsection 5.1, we describe the Paranaguá Port, the sensors and the support systems available to assist pilots. Next, in Subsection 5.2, we discuss the general case - the basic features of a port ready to receive autonomous ships. Finally, in Subsection 5.3, we propose solutions to implement in the Paranaguá Port and assist the autonomous ships in critical passages.

\subsection{Paranaguá Port nowadays}

Paraná Ports are a complex that includes the Paranaguá Port and the Antonina Port. The Paranaguá Port is one of the busiest ports in South America. It is located in Paraná state, in Southern Brazil, and is the main exporting port of agricultural products in the country, especially soybeans and soybean meal. Various ship types call this port; they include container ships, car carriers, tankers, bulk carriers, general cargo and passenger ships. A transportation mesh connects the East, Central and West Aisles in Southern Brazil and Mercosul Exportation Aisle. This mesh includes roads, railroads and oil pipelines.

To bring vessels to Paranaguá and Antonina ports, pilots embark on ships at open sea, in area $\mathrm{A}$ of the nautical chart shown in Figure 2. Ships enter the Galheta Channel, navigating through areas B, C, D and E. After sailing for 15 nautical miles, ships reach the Paranaguá Port, located in area G (Figure 3). Figure 3 also shows a channel in area H (in Paranaguá Bay) to access the Ponta do Félix Terminal, located in Antonina (the area I). Many improvements were implemented in these ports to assist pilots in their tasks, bringing more safety and efficiency to the manoeuvres. Paraná Ports are equipped with: 
(1) 7 maregraphs,

(2) 2 weather stations,

(3) 2 current sensors, in areas $\mathrm{F}$ and $\mathrm{G}$,

(4) 1 ODAS buoy, in area A,

(5) Shore AIS antenna,

(6) Cameras to check visibility,

(7) 1 anemometer and 1 anemoscope besides those in the weather stations, installed in Cattalini Terminal in area $\mathrm{G}$ and

(8) Pilot Station Traffic Control Centre.

Plate 7 shows the ODAS buoy installed by the pilotage in area A next to buoy number 1 of the Galheta Channel. The installation of the ODAS buoy by pilotage improved and expedited the assessment of the prevailing conditions and risks to the pilotage boarding and navigation. In severe weather conditions, waves, wind, sideways current and visibility in area A (Figure 2) may become too risky for pilots' boarding or disembarkation and even for navigation, since area $\mathrm{A}$ is about 15 nautical miles far from the port and the Pilot Station Traffic Control Centre. The data received from this buoy are available for pilots in the web-based system, as shown in Figure 4.

The data received from the equipment sensors are available at the Pilot Station. In addition, pilots on duty can access the data from personal computers, tablets and mobile phones through a web-based system. Besides the sensors' information, the system can inform pilots about expected traffic, ships' positions, AIS data, regulations and tide table. The Traffic Control Centre of the Pilot Station is shown in Plate 8. It is possible to contact pilots, tugs and vessels from this room to inform them about expected traffic, weather forecast, environmental conditions, current and tide. In addition, there are several sensors installed along the port area and Galheta Channel.

\subsection{The port features for autonomous ships}

Autonomous ships may be capable of navigating in the open sea without external interference or assistance in most situations. However, this may not be the case in restricted

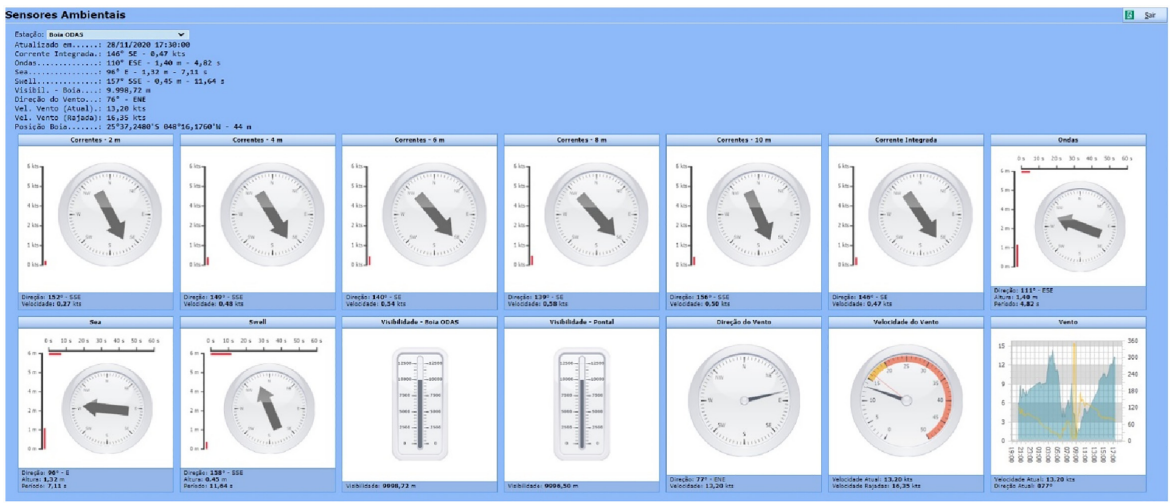

Source(s): Authors based on WebPilot (developed by All System)

Figure 4.

ODAS buoy information in the webbased information system 


\section{MABR 7,1}

\section{8}

Plate 8.

Pilot station's traffic control centre

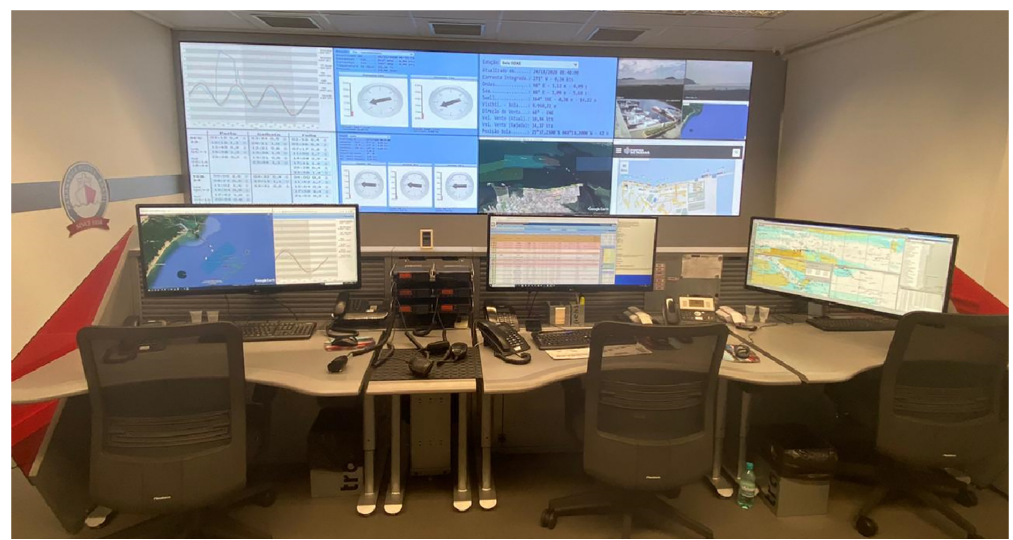

waters. Due to topographical peculiarities, the ports in general or the fairway control centres, in particular, should provide autonomous ships with all the relevant information to conduct safe navigation when in restricted pilotage waters. Sensors' data with redundancy and robust communication methods must be available. A control centre or a vessel traffic service (VTS) should manage the authorisations and schedules for sailing and manoeuvres.

Besides the sensors mentioned before (current, wind, waves, visibility sensors and maregraphs), the equipment available in the ports should include image recognition cameras, AIS and radars. All the equipment should have redundant systems to feed autonomous ships with the required data and assist the security team in preventing smuggling, piracy and stowaways. Sensors, cameras and AIS antennas should be placed in locations indicated by the pilots as areas of interest or critical areas.

The autonomous ships must be prepared for unforeseen situations, emergencies and poor communications during the passage in restricted waters. Therefore, contingency plans, available anchorages, abort points, expected traffic, no-go areas and depth changes should be informed to the autonomous ship before the beginning of the passage, always considering the draft, cargo, type of vessel and vessel manoeuvring capabilities. In addition, the port control centre should inform the autonomous ships of all the relevant information considered by the pilots, as any restriction or new regulation.

On the other hand, the autonomous ships should share information with the port's control centre to allow the port control to manage the traffic and information effectively. Each vessel should inform details of the passage plan, including planned route and speed, position, heading, turn rate, traffic in the vicinities (including small boats), environmental sensors data, manoeuvring restrictions and dangerous cargo echo sounder data and draft. If at any moment, the ship's situational awareness system identifies discrepancies, or if an action should be taken to avoid collision (Statheros et al., 2008), the port control centre should be informed immediately.

The information sent by the vessels to the port control centre can feed a database that will allow a decision support software/system to recommend actions/alternative routes, calculate meeting points, estimated times of arrival (ETA) and call tugs and mooring men (if necessary). This software might also compile all vessels' information to improve the data quality about the port conditions. The echo sounder data, for example, can indicate that the depths in the channel do not correspond to the information in the nautical chart. 
A piece of traffic management software at the control centre (Pietrzykowsk et al., 2018) should exchange and update information with all vessels in its range and assist the operators (Man et al., 2015) in decision-making.

\subsection{The Galheta Channel and autonomous shipping}

For both passages (the entrance and the passage in buoys 28A, 29, 30 and 31), the coordination of a port control centre for autonomous ships will be required. A digital coordination system at this control centre will collect the data from all available sensors, loading/discharging completion time, traffic, tugs and any other information that may be required during the passages. Information will be exchanged, through a reliable communication network, with all ships in the port area.

The autonomous ships should send, to the port control centre, information regarding

(1) Planned routes and speed.

(2) Ships' actual draft.

(3) Discrepancies in the charted information found by vessels during the passage allow the port control centre to track changes in channels depths and deficiencies in aid to navigation.

(4) Environmental information from ships' sensors (allowing the confirmation of the port sensors' data and expansion of the region covered by sensors).

(5) The ship's deficiencies.

(6) Targets without AIS (identified by the autonomous ship).

The port control centre should send, to the autonomous ship, information regarding

(1) Contingency plans, including those necessary in poor communication with the port control centre. The contingency plans must be updated whenever required by the circumstances.

(2) Position of known targets without AIS (obtained by shore-based radars, shore image recognition systems or informed by other ships).

(3) Environmental information from port sensors as well as those reported by other ships.

(4) Occupied berths and prospects of availability; occupied anchorages and prospects of availability; expected traffic; mooring men availability; space available in the berth; and tug availability.

(5) Known discrepancies in the charted information.

(6) Speed limits and another navigational requirement of the local regulations.

5.3.1 The entrance. The first challenge pilots face after boarding a ship in area A (Figure 2) is entering Galheta Channel between buoys 1 and 2 and navigating its first 2 nautical miles (between waypoints A1 and A2 in Figure 5). Out of the channel, on both sides, there are shallow areas. In the past, strong winds, big waves and strong sideways currents caused groundings in this region. Even when the conditions are not too extreme, if the pilot is not aware of them early enough, he may not avoid an accident.

Although the pilot boarding manoeuvre cannot be conducted at high speeds, to enter safely in the channel in unfavourable conditions, the ship has to proceed at sufficient speed, higher than in calm weather days, apply a leeway to compensate for the set and navigate 


\section{MABR \\ 7,1}

\section{0}

Figure 5.

Critical passage in the Paranaguá Port

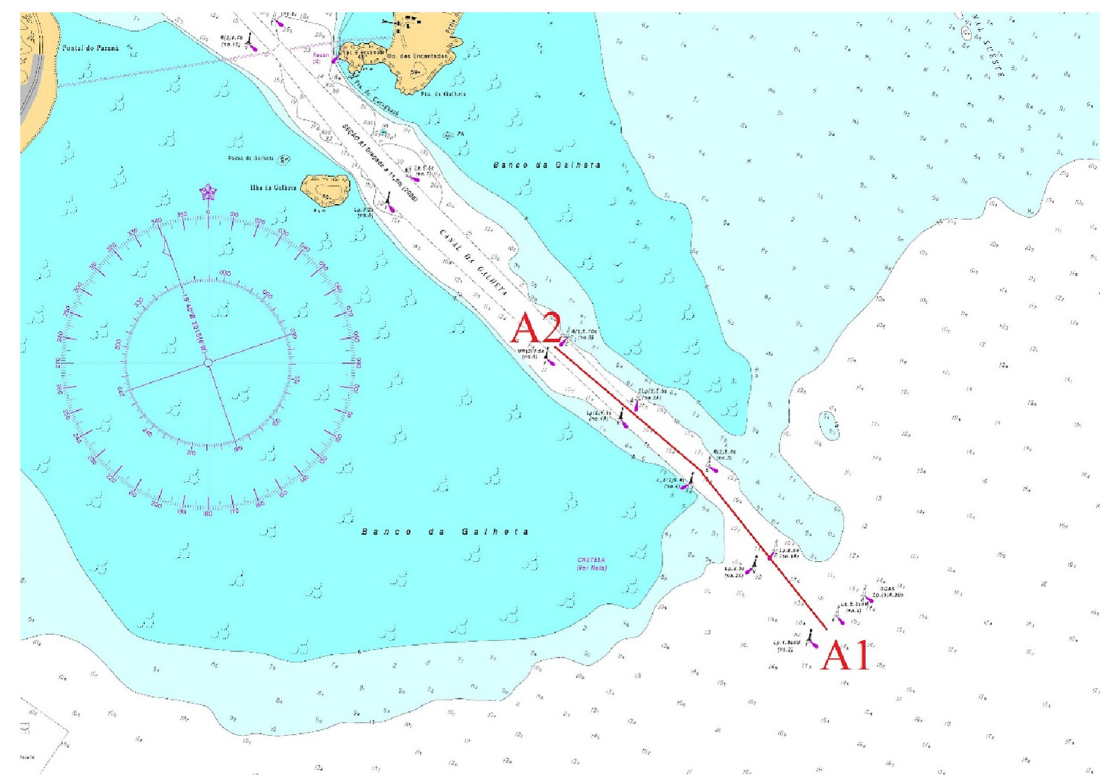

Source(s): Nautical Chart 1821 (Brazilian Navy)

closer to the buoys in the side opposite to the one she is being set to. Furthermore, meeting other vessels in this region is prohibited by regulations. This means that, after boarding the ship only 2 nautical miles before the channel's entrance, the pilot must be aware of the traffic, control the vessel's speed and adjust her course and heading to compensate for the external forces.

For the entrance of an autonomous ship in Galheta Channel, the port should provide various types of data to the vessel even before her approach. Time of berthing and unberthing manoeuvres is scheduled based on many criteria to avoid unacceptable risks. Among these criteria are the ship's draft, tide height, expected current direction and intensity during the berth/unberth manoeuvre, expected traffic, the ship's average speed, length of the passage and berth availability. After computing all these data, the port control centre can calculate the suitable time window for the autonomous ship's entrance or departure.

Besides the time window, the port control should provide the data about visibility, current, wind and tide regarding the area between A1 and A2 (Figure 5) and the expected traffic during the whole passage to the berth. In addition, dangers to navigation should be reported to the ship. Computing all these data, the autonomous ship could adjust course and speed or even abort the entrance if prevailing conditions are unsafe when approaching the channel's entrance.

5.3.2 Passage in buoys 28A, 29, 30 and 31. One of the most critical passages in the Paranaguá port is located in the region surrounded by the buoys $28 \mathrm{~A} / 30$ and 29/31 in the Galheta Channel. In this subsection, we will discuss some possible scenarios for the navigation of autonomous ships in this critical area. We considered 2 possible routes (F1 and F2) for the navigation. In Figure 6, the route F1, in red, pass across this region. It is narrow, and the vessel turns to pass between buoys. There are rocks on both sides, and the resultant current and wind forces may set the vessels sideways towards the rocks. 


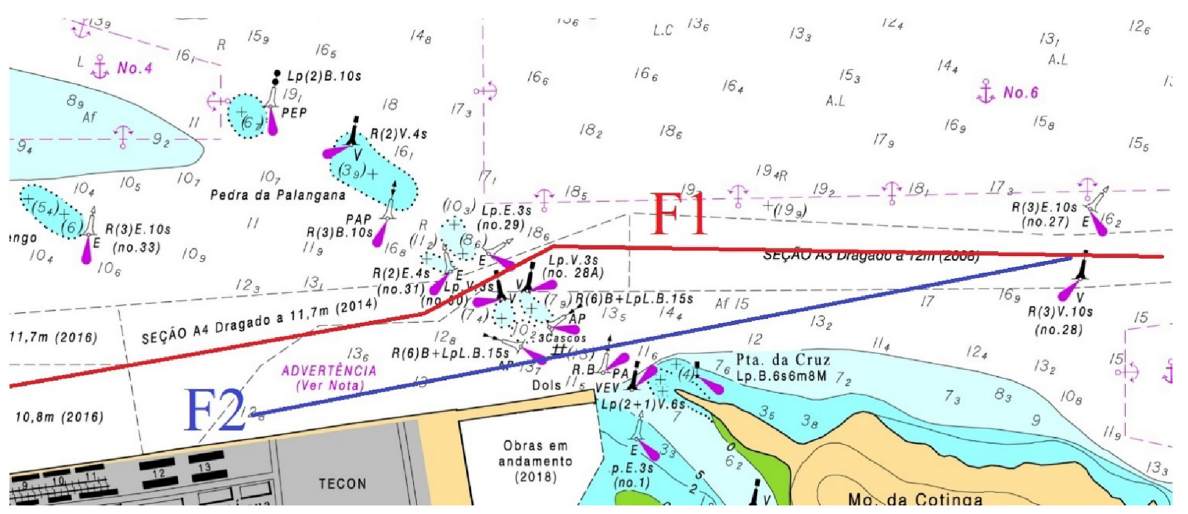

Source(s): : Nautical chart 1822 (Brazilian Navy)

\section{Autonomous} ships

According to the pilots, the speed should be in an interval that allows making fast tugs safely and avoiding excessive drift. The planned route should be closer to the buoys on the side that is opposite to the set. Nevertheless, if current and wind are not strong, the ship can proceed in the middle of the channel at lower speeds. If the draft is high, the passage should be conducted in high water.

The port should provide an autonomous ship with the following information regarding the critical area: availability of tugs and predicted current, wind, visibility, tide height and traffic at the expected time of the passage. The autonomous ship must process all these data in advance to adjust the speed to reach that area in the high water, without strong currents, avoid dangerous meetings with other vessels and have tugs available. Before the ship is affected by the lateral forces, her route should be corrected to compensate for the set while turning to pass between buoys. If the ship ignores the information from the port and proceeds in the middle of the channel at low speed, she may run aground in the rocks even if she reacts immediately to the external forces.

The autonomous ship could consider taking the alternative route F2. Although wind and lateral current may affect the vessel during passage $\mathrm{F} 2$, this route is straight and wider than passage F1. Therefore, it seems to be a better option. However, there may be ships alongside area F2 limiting the sea room and the maximum safe speed for the passage. Besides, gantry cranes may be operating and reducing the maximum safe air draft and channel width. All this information should be available to the ships and computed when choosing the preferred route.

One vessel on a head-on situation with other ship could take route F1, and the other ship could take route $\mathrm{F} 2$ to avoid a collision. To accomplish the meeting manoeuvre, they should exchange routes in advance. The port control centre should coordinate the meeting considering the size of ships, cargo, draft, vessels alongside, windage area, speed, vessels alongside and environmental forces.

Nowadays, there is a current sensor installed in area F1 and a maregraph in area F2. There is another current sensor about 2 miles from this area. Extra anemometres, anemoscopes and visibility sensors should be installed as close as possible to areas F and G. Additionally, the communication systems should be improved to become more reliable. Image recognition cameras should inform about any obstacle found in the fairway, and all the sensors must be at least duplicated. The pilot station currently conducts the traffic control, but the autonomous ships will require an upgraded coordination centre to exchange data, make recommendations and give authorisations. 


\section{MABR}

7,1

\section{Conclusions}

Autonomous ships can navigate the open sea, recognise objects (Khellal et al., 2018) and change course/speed to avoid collision (Johansen et al., 2016). Nevertheless, when it comes to restricted waters, other challenges arise and, to overcome them, ports prepared to receive such vessels should be designed. Pilotage will play a critical role in upgrading ports to receive autonomous ships. Pilots have the skills and knowledge to identify critical areas and factors to be taken into account during navigation. They are the best professionals to prepare passage and contingency plans to be shared with the unmanned vessels.

New equipment and software will be necessary for ports, although some parts of this complex system may already be available nowadays. The existing types of equipment could be integrated into the control centre system for autonomous ships. A robust port coordination centre can manage traffic, communications and concentrate sensors' and ships' data, constantly evaluating prevailing conditions and vessels' particulars. The port's equipment must be designed to provide early and reliable information to autonomous ships, allowing them to anticipate external influences and previously compensate it instead of reacting only when they are already being affected. Safe navigation in these areas will result from autonomous ships and ports working together as one complex system.

\section{References}

Almeida, T.S., Mumme, N.M. and Novaes, D.F.C. (2019), "A importância do serviço de praticagem para o cotidiano portuário, um estudo de sua atuação no porto de santos", Revista Processando o Saber, Vol. 11 No. 1, pp. 84-101, 1 out. 2019.

Boogaard, M.V.D., Feys, A., Overbeek, M., Le Poole, J. and Hekkenberg, R. (2016), "Control concepts for navigation of autonomous ships in ports", 10th Symposium on High-Performance Marine Vehicles - HIPER'16.

Burmeister, H.-C., Bruhn, W., Rødseth, Ø.J. and Porathe, T. (2014), "Autonomous unmanned merchant vessel and its contribution towards the e-navigation implementation: the MUNIN perspective", International Journal of e-Navigation and Maritime Economy, Vol. 1, pp. 1-13.

Fiedler, R., Bosse, C., Gehlken, D., Brümmerstedt, K. and Burmeister, H.S. (2019), Autonomous Vehicles' Impact on Port Infrastructure Requirements, Fraunhofer Center for Maritime Logistics and Services CML, Hamburg.

International Maritime Pilots' Association (2020), "Becoming a pilot", available at: https://www. impahq.org/becoming_a_pilot.php.

Johansen, T.A., Perez, T. and Cristofaro, A. (2016), "Ship collision avoidance and COLREGS compliance using simulation-based control behavior selection with predictive hazard assessment", IEEE Transactions on Intelligent Transportation Systems, Vol. 17 No. 12, pp. 3407-3422, doi: 10.1109/TITS.2016.2551780.

Khellal, A., Ma, H. and Fei, Q. (2018), "Convolutional neural network based on extreme learning machine for Maritime ships recognition in infrared images", Sensors, Vol. 18, p. 1490, doi: 10. 3390/s18051490.

Lee, S., Roh, M., Lee, H., Ha, J. and Woo, I. (2018), "Image-based ship detection and classification for unmanned surface vehicle using real-time object detection neural networks", Proceedings of the Twenty-Eighth (2018) International Ocean and Polar Engineering Conference.

Lyu, H. and Yin, Y. (2018), "Fast path planning for autonomous ships in restricted waters", Applied Sciences, Vol. 8 No. 12, p. 2592, doi: 10.3390/app8122592.

Man, Y., Lundh, M., Porathe, T. and MacKinnon, S. (2015), "From desk to field - human factor issues in remote monitoring and controlling of autonomous unmanned vessels", 6th International Conference on Applied Human Factors and Ergonomics and the Affiliated Conferences, doi: 10. 1016/j.promfg.2015.07.635. 
Perera, L.P., Ferrari, V., Santos, F.P., Hinostroza, M.A. and Guedes Soares, C. (2015), "Experimental evaluations on ship autonomous navigation and collision avoidance by intelligent guidance", Journal of Oceanic Engineering (IEEE), Vol. 40 No. 2, pp. 374-387, doi: 10.1109/JOE.2014. 2304793.

Pietrzykowsk, Z., Magaj, J. and Wielgosz, M. (2018), "Navigation decision support for sea-going ships in port approach areas", Scientific Journals of the Maritime University of Szczecin, Vol. 54 No. 126, pp. 75-83, doi: 10.17402/288.

Statheros, T., Howells, G. and Klaus, M. (2008), "Autonomous ship collision avoidance navigation concepts, technologies and techniques”, Journal of Navigation, Vol. 61 No. 1, pp. 129-142, doi: 10. 1017/S037346330700447X.

Wahlström, M., Forster, D., Karvonen, A., Puustinen, R. and Saariluoma, P. (2019), "Perspective-taking in anticipatory Maritime navigation - implications for developing autonomous ships", in Volker, B. (Ed.), 18th International Conference on Computer and IT Applications in the Maritime Industries, Technische Universität Hamburg-Harburg, Tullamore, pp. 191-200.

\title{
Further reading
}

Amendola, J., Miura, L.S., Costa, A.H.R., Cozman, F.G. and Tannuri, E.A. (2020), "Navigation in restricted channels under environmental conditions: fast-time simulation by asynchronous deep reinforcement learning", IEEE Access, Vol. 8, pp. 149199-149213, doi: 10.1109/access.2020. 3015661.

Dijk, T., Dorsser, H., Berg, R., Moonen, H. and Negenborn, R.R. (2018), Smart Ships and the Changing Maritime Ecosystem.

Höyhtyä, M., Huusko, J., Kiviranta, M., Solberg, K. and Rokka, J. (2017), "Connectivity for autonomous ships: architecture, use cases, and research challenges", 8th International Conference on ICT Convergence, doi: 10.1109/ICTC.2017.8191000.

\begin{abstract}
About the authors
Helio Takahiro Sinohara, Doctorate student at the Department of Mechanics Engineering, Escola Politécnica, University of São Paulo (EPUSP) and at the Maneuvering Simulation Center of the Numerical Offshore Tank (TPN). He was graduated in Computer Engineering in 1998 and completed his MSc in 2001, both at Pontifícia Universidade Católica do Rio de Janeiro (PUC-Rio). He worked as an Amazon River pilot from 2010 to 2017 and has been working as a harbour pilot at Paranaguá and Antonina ports since 2017. He is engaged in artificial intelligence and autonomous ship projects. Helio Takahiro Sinohara is the corresponding author and can be contacted at: professorsinohara@futurehouse.com.br

Eduardo Aoun Tannuri, Full Professor at the Department of Mechatronics Engineering, Escola Politécnica, University of São Paulo (EPUSP) and coordinator of the Maneuvering Simulation Center of the Numerical Offshore Tank (TPN). He is also the Member of ITTC Maneuvering Committee (2012-2020). His research works are on Dynamic Positioning (DP) Systems applied to offshore vessels and platforms, Maneuvering and Sea-keeping time-domain simulators development with applications to ports, vessels and floating structures design.
\end{abstract}

For instructions on how to order reprints of this article, please visit our website:

www.emeraldgrouppublishing.com/licensing/reprints.htm

Or contact us for further details: permissions@emeraldinsight.com 